\title{
PROBLEMATIKA WAKTU IHTIYATH DALAM PEMBUATAN JADWAL SHALAT
}

\author{
Nanda Trisna Putra \\ Fakultas Syariah UIN Maulana Malik Ibrahim Malang \\ nandatrisna@gmail.com
}

\begin{abstract}
Abstrak
The purpose of this research is to find the problems in Ihtiyath in determining the pray time and to know the law status of prayer during the time. The result shows an ambivalent position between Ihtiyath definition issued by the Ministry of Religious Affairs with its application. According to the Ministry of Religious Affairs, Ihtiyath is a security way by adding or subtracting the time in order that pray time schedule does not precede the beginning of time, or beyond the end of time and the law status of someone who prays in Ihtiyath time is posing two possibilities. The first possibility, if someone prays one rakaat completely with its sujud while time is essential, on second rakaat comes to Ihtiyath time so this pray is still judged as qadlaan. The second possibility is that, if someone pray incompletely one rakaat with its sujud then Ihtiyath time comes, this pray is judged qadlaan.

Tujuan dari penelitian ini adalah untuk menemukan masalah-masalah dalam Ihtiyath dalam menentuan waktu sholat dan mengetahui status hukum dari orang yang sholat pada waktu ihtiyath. Hasil penelitian menunjukkan bahwa ada posisi ambivalen antara Ihtiyath yang ditentukan oleh Kementerian Agama dengan aplikasinya. Menurut Kementerian Agama, Ihtiyath adalah suatu cara pengaman melalui penambahan atau pengurangan waktu agar waktu sholat tidak mendahuli awal sholat atau diluar dari akhir wktu sholat dan status hukum orang yang sholat pada waktu ihtiyath memiliki dua kemungkinan. Kemungkinan pertama, jika seseorang sholat satu rakaat dilengkapi dengan sujud pada sebelum ikhtiyath dan pada rakaat kedua ihtiyath masuk, maka sholatnya dihukumi sebagai qadlaan. Kemungkinan kedua, jika seseorang sholat pada rakaat pertama tidak dilengkapi dengan sujud kemudian ikhtiyath masuk, maka sholatnya dihukumi sebagai qadlaan
\end{abstract}

Kata kunci: Ihtiyath, Pray schedule, Astronomy, Islamic Jurisprudence.

Shalat merupakan ibadah yang terdiri dari perkataan dan perbuatan tertentu yang dimulai dengan takbir dan disudahi dengan memberi salam. Shalat adalah ibadah yang terpenting dan utama dalam Islam. Dalam rukun Islam, Rasulullah saw memposisikannya pada posisi kedua setelah mengucapkan dua kalimat syahadat (syahadatain). Karena Ibadah shalat merupakan ibadah yang telah ditentukan syariat, maka pelaksanaan shalat seorang muslim haruslah sesuai dengan tuntunan yang ada pada Al Quran dan sunnah rasul. Dalam hadits mutawatir yang sering kita dengar Rasulullah SAW bersabda:

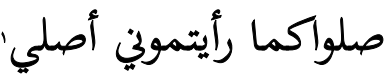

"Shalatlah kalian sebagaimana kalian melihatku shalat".

Al-Bukhari, Abu Abdillah Muhammad, Shahihul Bukhori Juz 1.Beirut: Dar el Kotob, 2010, h. 154
Shalat fardlu merupakan salah satu amaliah dalam Islam yang berhubungan dengan ruang dan waktu dalam pelaksanaannya. Keberadaan shalat baik yang fardu maupun yang sunnah dalam Islam menempati posisi yang penting, sehingga dapat kita temui banyak sekali ayat dan hadits yang berbicara masalah shalat, baik tata cara maupun hikmahnya. Seperti yang telah disebutkan di atas, shalat dalam pelaksanaannya berhubungan erat dengan ruang dan waktu. Al-Qur'an menegaskan:

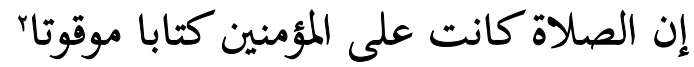

"Sesungguhnya shalat itu adalah kewajiban yang ditentukan waktunya atas orang-orang yang beriman." 
Sehingga secara syar'i, shalat yang diwajibkan (shalat maktubah) itu mempunyai waktu-waktu yang telah ditentukan (sehingga terdefinisi sebagai ibadah muaqqat). Hal ini berimplikasi pada shalat tidak bisa dikerjakan pada sembarang waktu atau sesuka mushollinya. Walaupun dalam Al Qur'an tidak dijelaskan secara gamblang waktu-waktunya, namun telah Al Qur'an menentukannya.

Dengan kemajuan yang telah dicapai manusia dalam bidang ilmu falak. Berangsur-angsur manusia menemukan metode-metode terbaru untuk menentukan awal waktu shalat berdasar hadist yang menerangkan batasan-batasan waktu shalat di atas. Sebagai contoh kemajuan dunia falak dalam penentuan awal waktu shalat ini adalah ditemukannya metode rubu', ephemeris, dan nautika. Penggunaan metode-metode terbaru tersebut muncul setelah ditemukannya jam yang terdiri dari satuan jam, menit, dan detik. Penggunaan metode ephemeris dan nautika diterapkan dengan memperhatikan Lintang Tempat $(\phi)$, Bujur Tempat $(\lambda)$, Deklinasi Matahari $\left(\delta^{\circ}\right)$, Equation of Time/Perata Waktu $\left(\mathrm{e}^{\mathrm{o}}\right)$, Tinggi Matahari $\left(\mathrm{h}^{\circ}\right)$, Koreksi Waktu Daerah (Kwd), dan Ihtiyath (i) dalam menentukan awal waktu shalat.

Adapun yang dimaksud Ihtiyath adalah suatu langkah pengamanan dalam menentukan waktu shalat dengan cara menambahkan atau mengurangkan waktu agar tidak mendahului awal waktu shalat atau tidak melampaui batas akhir waktu shalat. Para ahli hisab dalam menentukan waktu untuk Ihtiyath berbedabeda, ada yang menetapkan 2 menit, 3 menit, atau 4 menit. Pendapat yang umum dipakai adalah 2 menit untuk waktu Ihtiyath (Depag RI, 1994:9). ${ }^{3}$ Langkah pengamanan ini perlu dilakukan disebabkan beberapa hal, antara lain: (a) adanya pembulatan-pembulatan dalam pengambilan data walaupun pembulatan itu sangat kecil. demikian pula hasil perhitungan biasanya diperoleh dalam satuan detik, maka untuk penyederhanaan pengamanan perlu dilakukan pembulatan sampai satuan menit, (b) jadwal waktu shalat diberlakukan untuk beberapa tahun atau sepanjang masa, sedangkan data yang dipergunakan diambil dari tahun tertentu atau secara rata-rata data matahari dari tahun ke tahun ada perubahan meskipun sangat kecil. Perubahan ini akan menimbulkan pula perubahan jadwal waktu shalat, walaupun sedikit, (c) penentuan data lintang dan bujur tempat suatu kota biasanya diukur pada suatu titik (markaz) pusat kota. Setelah kota itu mengalami perkembangan, maka luas kota akan bertambah dan tidak menutup kemungkinan daerah

3 Moh. Murtado, Ilmu Falak Praktis, (Malang: Uin Press, 2008), h. 193 yang asalnya pusat kota kemudian berubah menjadi pinggiran kota. Akibat dari perkembangan ini ujung timur atau ujung barat suatu kota akan mempunyai jarak yang cukup jauh dari titik penentuan lintang dan bujur kota semula. Maka jika hasil perhitungan awal waktu shalat tidak ditambah Ihtiyath, ini berarti hasil tersebut hanya berlaku untuk titik markaz dan daerah sebelah timurnya saja, tidak berlaku untuk daerah sebelah baratnya. ${ }^{4}$

Penggunaan metode-metode terbaru ini yang menyertakan ihtiyath pada sisi positif menghasilkan manfaat yang besar karena dengan metode tersebut umat Islam dapat menentukan awal masuknya waktu shalat jauh sebelum waktunya tiba dan bisa mengantisipasi datangnya waktu shalat, sehingga umat Islam dapat membuat jadwal shalat setiap bulan dan tahunnya. Bahkan dengan metode ini umat Islam mampu membuat jadwal shalat abadi. Sehingga Pemerintah dan Ormas besar seperti NU dan Muhammadiyah menggunakan metode ini untuk menentukan awal waktu shalat. Tetapi bukan berarti penggunaan metode yang menambahkan ihtiyath ini tidak menyisakan problem.

Dengan kata lain, tujuan penambahan ihtiyath satu menit, dua menit, atau selebihnya adalah untuk antisipasi agar jangan sampai ada seseorang yang shalat sebelum waktunya tiba atau shalat saat waktunya telah habis, dan sebagai usaha penyeragaman waktu shalat pada suatu daerah yang wilayahnya luas.

Pada awalnya peneliti mendukung dan setuju dengan konsep ini, tetapi kemudian peneliti melihat konsep ihtiyath ini menimbulkan permasalahan dalam praktek perhitungannya. ihtiyath sebagai langkah pengamanan dalam menentukan waktu shalat dengan cara menambahkan atau mengurangkan waktu agar tidak mendahului awal waktu shalat atau tidak melampaui batas akhir waktu shalat. Definisi yang diajukan para ahli tersebut tidak benar-benar dilaksanakan pada praktek perhitungannya. Pada penggunaan metode ephemeris dan nautika misalnya, dalam penghitungan jadwal setiap shalatnya semua menambahkan ihtiyathnya, kecuali dalam penentuan awal waktu syuruq yang berarti penentuan akhir waktu shalat shubuh. Penggunaan metode ephemeris dan nautika sebagai contohnya, kedua metode tersebut diterapkan dengan memperhatikan Lintang Tempat $(\phi)$, Bujur Tempat $(\lambda)$, Deklinasi Matahari $\left(\delta^{\circ}\right)$, Equation of Time/Perata Waktu ( $\left.\mathrm{e}^{\circ}\right)$, Tinggi Matahari $\left(h^{\circ}\right)$, Koreksi Waktu Daerah (Kwd), dan ihtiyath (i).

\footnotetext{
4 Susiknan Azhari, Ilmu Falak Teori dan Praktek (Yogyakarta: Lazuardi , 2001), h. 87
} 
Kesimpulan yang dapat diambil dari rumus di atas yang berkaitan dengan pembahasan ihtiyath adalah setelah seluruh data yang terdiri dari Lintang Tempat $(\phi)$, Bujur Tempat $(\lambda)$, Deklinasi Matahari $\left(\delta^{\circ}\right)$, Equation of Time/Perata Waktu $\left(\mathrm{e}^{\circ}\right)$, Tinggi Matahari $\left(\mathrm{h}^{\mathrm{o}}\right)$, Koreksi Waktu Daerah (Kwd) dihitung, hasil perhitungan tersebut kemudian ditambah ihtiyath (i). Yang berarti jika ditambah ihtiyath misalnya 2 menit (seperti ihtiyath Depag RI), maka waktu shalat yang sebenarnya mundur 2 menit dan berimplikasi pada memanjangnya waktu shalat selama 2 menit dan mundurnya waktu shalat setelahnya selama 2 menit. Dengan demikian, penulis menyimpulkan bahwa terdapat kesenjangan antara hadits penentuan waktu shalat di atas dengan penerapan metode terbaru dalam menentukan awal waktu shalat.

Problematika ihtiyath di atas mengusik dan menarik perhatian penulis, sehingga muncul keinginan penulis untuk melakukan identifikasi dan memecahkan masalah Ihtiyath ini yang selama ini seolah buah simalakama. Niat awal penulis adalah menemukan solusi terbaik pada problematika ini. Karena penulis melihat masalah ini sebagai masalah umat Islam.

Berdasarkan persoalan-persolan di atas, peneliti menyusun rumusan masalah sebagai berikut (1) Apakah problematika ihtiyath waktu shalat?, (2) Bagaimana hukum seseorang yang shalat dalam masa ihtiyath?

Adapun manfaat penelitian ini diharapkan dapat memberikan sumbangsih pemikiran bagi disiplin keilmuan secara umum dan sekurang-kurangnya bermanfaat dalam dua aspek, yaitu aspek teoritis dan praktis. Secara teoritis, penelitian ini diharapkan mampu menambah khazanah keilmuan dalam bidang falak, khususnya dalam perhitungan awal waktu shalat, serta penelitian ini diharapkan menjadi referensi awal munculnya penelitian yang melahirkan teori-teori Ihtiyath baru. Secara praktis, penelitian ini diharapkan mampu memberikan pemahaman kepada masyarakat awam bahwa jadwal waktu shalat yang ada selama ini telah ditambah Ihtiyath, sehingga diharapkan pada masyarakat agar melaksanakan shalat pada awal waktu, jika terpaksa harus mengakhirkan shalat, maka diharapkan pada masyarakat agar melaksanakan shalat pada waktu yang tidak terlalu mendekati waktu shalat setelahnya.

\section{Metode Penelitian}

Merujuk pada latar belakang dan rumusan masalah yang diambil, maka penelitian ini di- kategorikan sebagai penelitian hukum normatif. Penelitian hukum normatif adalah penelitian hukum kepustakaan. Penelitian ini membahas ihtiyath dalam penentuan awal waktu shalat beserta hukum melaksanakan shalat saat masa tersebut. Dalam penelitian ini, peneliti menggunakan dua pendekatan, yaitu pendekatan kualitatif dan pendekatan kuantitatif. Menurut Bogdan dan Taylor mendefinisikan pendekatan kualitatif sebagai prosedur penelitian yang menghasilkan data deskriptif berupa kata-kata ataupun tulisan. ${ }^{5}$ Sedangkan pendekatan kuantitatif adalah prosedur penelitian yang menghasilkan data berupa angka-angka. Aplikasi pendekatan kuantitatif pada penelitian ini terdapat pada permasalahan yang pertama, yakni penemuan problem dalam konsep ihtiyath. Sedangkan untuk pendekatan kualitatif, peneliti menggunakannya untuk memperoleh datadata hukum berupa literatur-literatur fiqh tentang waktu shalat yang dijadikan pisau analisis pada pembahasan hukum shalat saat masa ihtiyath .

Sumber data dalam penelitian merupakan persoalan dimana data dapat ditemukan. ${ }^{6}$ Dalam penelitian ini, peneliti menggunakan jenis sumber data sekunder.Kemudian sumber data sekunder ini dibagi oleh peneliti menjadi: ${ }^{7}$ (1) Bahan Hukum Primer, yaitu bahan-bahan hukum yang mengikat. Yang dalam hal ini meliputi al Quran. Hadits sebagai mashadir hukum dalam ajaran Islam, kitab-kitab fiqh syafiiyyah, dan jadwal waktu shalat. Tentunya dari semua bahan hukum primer, dipilih bahan-bahan hukum yang berkaitan dengan bahasan tentang waktu shalat. (2) Bahan Hukum Sekunder, yang memberikan penjelasan mengenai bahan hukum primer, seperti: (a) Pedoman Penentuan Jadwal Waktu Shalat Sepanjang Masa terbitan Depag .tahun 1994. (b) Encup Supriatna, Hisab Rukyat dan Aplikasinya. Refika Aditama. Bandung. (c) Moh murtado. Ilmu Falak Praktis. 2008. Uin press. Malang. (d) Susiknan Azhari. Ilmu Falak Teori dan Praktek Lazuardi. Yogyakarta. (e) Jayusman, Dosen Fakultas Ushuluddin IAIN Raden Intan Lampung, http: //jayusmanfalak.blogspot.com. (3) Bahan Hukum Tersier, yakni bahan yang memberikan petunjuk maupun penjelasan terhadap bahan hukum primer dan sekunder, termasuk dalam bahan tersier ini adalah kamus, ensiklopedia dan Google Earth Pro sebagai peta. Kemudian peneliti meng-

\footnotetext{
5 Lexy J. Moleong, Metodologi Penelitian Kualitatif (Bandung: PT Remaja Rosdakarya, 2002), h. 3.

6 Sutrisno Hadi, Metodologi Research Jilid I (Yogyakarta:Andi offset,1993), h. 66 .

7 Soerjono Soekanto, Pengantar Penelitian Hukum (Jakarta: UI Press, 1986), h. 52 .
} 
gunakan studi dokumen atau dokumentasi untuk alat pengumpul datanya. Studi dokumen merupakan langkah awal dari setiap penelitian hukum. Studi dokumen bagi penelitian hukum meliputi studi bahanbahan hukum yang terdiri dari bahan hukum primer, bahan hukum sekunder, dan bahan hukum tersier. ${ }^{8}$

Pada bagian analisis, Peneliti menggunakan metode analisis deskriptif yaitu analisis data yang mendasarkan pada isi dari data deskriptif. ${ }^{9}$ Setelah melihat dan mempelajari konsep penentuan awal waktu shalat yang menggunakan Ihtiyâth sebagai salah satu instrument yang diperhitungkan, peneliti menggunakan ilmu falak sebagai pisau analisis data pelengkap masalah utama yang tercantum dalam rumusan masalah. Sebagai pisau analisis utama dalam bidanghukum shalat di masa ihtiyâth, peneliti akan menggunakan kajian fikih Syafi'iyah sebagai piranti analisis hukumnya. Selanjutnya peneliti mengemukakan kesimpulan dari inti permasalahan dalam rumusan masalah tentang hukum shalat saat masa ihtiyâth.

\section{Hasil dan Pembahasan}

Pada buku Pedoman Penentuan Jadwal Waktu Shalat Sepanjang Masa terbitan Depag tahun 1994 tertulis Ihtiyath merupakan langkah pengamanan dengan cara menambahkan atau mengurangkan waktu agar jadwal waktu shalat tidak mendahului awal waktu atau melampaui akhir waktu. Langkah pengamanan ini perlu dilakukan disebabkan adanya beberapa hal, antara lain: (1) Adanya pembulatan-pembulatan dalam pengambilan data walaupun pembulatan itu sangat kecil. Demikian pula hasil akhir perhitungan biasanya diperoleh dalam bentuk satuan detik, maka untuk penyederhanaan pengamanan perlu dilakukan pembulatan sampai satuan menit. (2) Jadwal waktu shalat diberlakukan untuk berpuluh tahun atau sepanjang masa, sedangkan data yang dipergunakan diambil dari tahun tertentu atau secara rata-rata. Data matahari dari tahun ke tahun ada perubahan walaupun sangat kecil. Perubahan ini akan menimbulkan pula perubahan jadwal waktu shalat. (3) Penentuan data lintang dan bujur tempat suatu kota biasanya diukur pada suatu titik (markaz) pusat kota. Setelah kota itu mengalami perkembangan, maka luas kota akan bertambah dan tidak menutup kemungkinan daerah yang asalnya pusat kota kemudian berubah menjadi

\footnotetext{
8 Amiruddin dan Zainal Asikin, Pengantar Metode Penelitian Hukum (Jakarta: PT. Raja Grafindo Persada, 2004), h. 68.

9 Cholid Narbuko dan Abu Achmadi, Metodologi Penelitian (Jakarta: PT Bumi Aksara, 2005), h. 65.
}

pinggiran kota. Akibat dari perkembangan ini ujung timur atau ujung barat suatu kota akan mempunyai jarak yang cukup jauh dari titik penentuan lintang dan bujur kota semula. Maka jika hasil perhitungan awala waktu shalat tidak ditambah Ihtiyath, ini berarti hasil tersebut hanya berlaku untuk titik markaz dan daerah sebelah timurnya saja, tidak berlaku untuk daerah sebelah baratnya. (daerah sebelah timur mengalami waktu lebih dahulu dari daerah baratnya).

Jadwal waktu shalat untuk suatu kota dipergunakan pula oleh daerah sekitarnya yang tidak terlalu jauh, seperti untuk jadwal kota kabupaten dipergunakan oleh kota-kota kecamatan sekitarnya. Agar supaya keadaan seperti itu tidak keliru maka diperlukan adanya Ihtiyathi. Nilai Ihtiyathi yang dipakai oleh H. Saadoeddin Jambek adalah sekitar 2 menit. Ada pula para ahli hisab yang menentukan lebih dari 2 menit seperti terlihat pada waktu shalat Almanak Menara Kudus dimana waktu Dzuhur ditetapkan selalu jam 12.04, pada hal untuk waktu istiwa dinyatakan bahwa matahari berkulminasi jam 12.00 ini berarti ada unsur Ihtiyathi sebanyak 4 menit. Direktorat badan pembinaan badan peradilan agama Islam mempergunakan Ihtiyathi sekitar 2 menit seperti dikemukakan H. Saadoeddin Jambek, kecuali jika jadwal dimaksud dipergunakan oleh daerah sekitar $30 \mathrm{~km}$. Nilai Ihtiyathi 1-2 menit sudah diaggap cukup memberikan pengamanan terhadap pembulatanpembulatan dan rata-rata, juga mempunyai jangkauan 27,5 sampai $55 \mathrm{~km}$ ke arah barat dan timur. ${ }^{10}$

Uraian di atas pada intinya menerangkan bahwa Ihtiyath menurut Depag merupakan langkah pengamanan dengan cara menambahkan atau mengurangkan waktu agar jadwal waktu shalat tidak mendahului awal waktu atau melampaui akhir waktu. Kemudian peneliti dapati dalam rumus aplikasi perhitungan jadwal waktu shalat sebagai berikut:

$\begin{array}{lll}\text { Dhuhur } & =(12-\mathrm{e})+\mathrm{Kwd}+\mathrm{i} \\ \text { Ashar } & =(12-\mathrm{e})+(\mathrm{t} / 15)+\mathrm{Kwd}+\mathrm{i} \\ \text { Maghrib, Isya' } & =(12-\mathrm{e})+(\mathrm{t} / 15)+\mathrm{Kwd}+\mathrm{i} \\ \text { Imsak } & =(12-\mathrm{e})-(\mathrm{t} / 15)+\mathrm{Kwd}+\mathrm{i} \\ \text { Subuh } & =(12-\mathrm{e})-(\mathrm{t} / 15)+\mathrm{Kwd}+\mathrm{i} \\ \text { Syuruq } & =12-\mathrm{e}-\mathrm{t}+\mathrm{Kwd}-\mathrm{i}\end{array}$

Dari rumus di atas,peneliti menemukan fakta bahwa Ihtiyath dalam proses perhitungan jadwal waktu shalat hanya ditambahkan pada akhir perhitungan, selain waktu syuruq. Tentunya aplikasi rumus ini berbeda dengan definisi Ihtiyath di atas

10 Depag, Pedoman, h. 38 
yang menyatakan adanya proses penambahan dan pengurangan waktu shalat.

Menurut hemat peneliti, jika memang Depag RI bersikukuh dengan statemen Ihtiyath adalah upaya menambahkan atau mengurangkan waktu agar jadwal waktu shalat tidak mendahului awal waktu atau melampaui akhir waktu, seharusnya Depag RI memperhitungkan berapa menit tambahan Ihtiyath yang diberlakukan, agar daerah bagian timur markaz tidak terlampau lama mengalami perpanjangan waktu, atau dalam setiap waktu shalat dihitung awal dan akhir waktunya, sehingga tidak seperti jadwal shalat yang ada selama ini. Jadwal shalat yang ada selama ini menerapkan awal waktu ashar menandai akhir waktu dzuhur, begitu juga akhir waktu ashar yang menandai awal masuk waktu maghrib. Padahal, hasil dari perhitungan awal waktu shalat tersebut telah mengalami penambahan Ihtiyath kurang lebih sekitar 2 menit.

\section{Konsekuensi penambahan Ihtiyath}

Sinar matahari sebagai pertanda perjalanan masa siang malam dalam satu hari, matahari memulai pancaran sinarnya dari bagian timur bumi terlebih dahulu.Dan shalat adalah ibadah yang berpedoman pada peredaran sinar matahari sebagai acuan waktu pelaksanaanya. Maka, merupakan konsekuensi logis jika daerah bumi bagian timur akan memasuki waktu shalat terlebih dahulu dibandingkan bagian bumi sebelah baratnya. Hal tersebut tentunya juga mengakibatkan waktu shalat daerah bumi bagian timur akan habis terlebih dahulu daripada bagian baratnya. Sebagai contoh penjelasan, karena matahari berjalan dari timur ke barat, maka daerah Malang timur akan memasuki waktu shalat terlebih dahulu dan habis terlebih dahulu dibanding daerah Malang bagian baratnya.

Pemberlakuan jadwal shalat yang mengacu pada satu titik markaz untuk daerah sekitar markaz telah menggeser peran penentuan shalat yang sebenarnya yakni menggunakan pedoman pergerakan sinar matahari yang mengawali penyinarannya dari bumi bagian timur. Selain itu, penyeragaman waktu shalat dalam satu daerah akan menjadikan daerah sekitar markaz akan menyesuaikan dengan waktu markaz, padahal secara hakiki tentunya ada perbedaan dalam awal dan akhir waktunya, seperti daerah Malang yang meliputi Poncokusumo di bagian timur dan Ngantang di bagian barat. Untuk daerah Malang, markaz sebagai patokan dasar wilayah perhitungan yang meliputi lintang dan bujur berada di tengah- tengah wilayahnya. Tentunya awal masuk waktu Dzuhur untuk daerah Poncokusumo pada hakikatnya berbeda dengan daerah markaz yang berada di tengah kota, demikian juga dengan wilayah Ngantang yang terletak di bagian Malang barat.Jika diberlakukan tambahan Ihtiyath, maka akan memunculkan selisihselisih waktu yang lebih besar daripada antar awal waktu hakiki bagian timur markaz, tengah, dan barat markaz.

Jika mengacu pada aplikasi perhitungan jadwal waktu shalat yang ternyata hanya menambahkan tanpa mengurangkan nilai Ihtiyath, maka berakibat pada mundurnya waktu shalat sebelumnya. Sebagai misal, pada suatu daerah awal waktu maghrib masuk pada jam 18.00. Karena ditambah Ihtiyath dengan harga dua menit versi depag, maka waktu maghrib menjadi 18.02 danadzan maghrib dikumandangkan saat itu juga. Adzan maghrib merupakan pertanda telah masuk waktu maghrib sekaligus sebagai pertanda berakhirnya waktu ashar. Konsekuensi logisyang muncul adalah mundurnya waktu shalat sebelumnya yaitu shalat ashar selama dua menit. Dan untuk daerah bagian timur dan barat daerah markaz juga menyesuaikan daerah markaz. Tentunya penyesuaian ini menimbulkan beberapa konsekuensi. Dari daerah markaz menuju arah timur maka nilai Ihtiyathnya akan semakin besar dan jika menuju ke barat maka nilai Ihtiyathnya semakin kecil.

Pada aplikasi perhitungannya,tambahan Ihtiyath dua menit itu berlaku mulai daerah markaz. Sehingga jika markaz berada di bagian timur kota, maka dua menit tersebut akan mencapai 55,5 km ke bagian barat markaz.

Dari paparan di atas, penulis mendapatkan temuan bahwa penambahan Ihtiyath mengakibatkan dua hal yaitu: (1) Memperpanjang waktu shalat sebelumnya, (2) Semakin ke timur dari daerah markaz, maka nilai Ihtiyath akan semakin besar.

\section{Praktek Perhitungan}

Pada bagian ini peneliti akan menampilkan praktek perhitungan jadwal waktu shalat yang berlaku pada daerah Malang pada tanggal 31 Maret 2012. yang menggunakan Ihtiyath dan yang tidak menggunakan Ihtiyath.

Peneliti menghitung waktu shalat yang berlaku pada daerah Malang, terdiri dari wilayah paling timur kabupaten Malang yaitu daerah Poncokusumo, daerah Markaz yang terletak di sekitar kota Malang, dan daerah paling barat yaitu daerah Ngantang. Penentuan titik koordinat bujur dan lintang masing- 
masing wilayah tersebut menggunakan software aplikasi Google Earth Pro.

Melalui media software Google Earth Pro didapati data titik koordinat wilayah sebagai berikut: Wilayah Markaz dengan titik koordinat wilayah $112^{\circ}$ $36^{\prime} \mathrm{BT}$ dan $7^{\circ} 59^{\prime}$ LS. Wilayah Poncokusumo dengan titik koordinat wilayah $112^{\circ} 55^{\prime} \mathrm{BT}$ dan $7^{\circ} 59^{\prime} \mathrm{LS}$. Wilayah Ngantang dengan titik koordinat wilayah $112^{\circ} 18^{\prime} \mathrm{BT}$ dan $7^{\circ} 49^{\prime} \mathrm{LS}$.

Selanjutnya, sebagai contoh peneliti akan menghitung waktu shalat Dzuhur dan Ashar dengan berpedoman pada masing-masing titik koordinat wilayah di atas. Dengan tujuan setelah mendapatkan hasilnya, peneliti akan mendapatkan nilai selisih antar wilayah dan mengetahui selisih antara waktu masuk shalat hakiki masing-masing wilayah dengan awal waktu yang ditetapkan oleh Kemenag, dalam hal ini peneliti menggunakan data jadwal waktu shalat yang dibuat oleh Kantor Kemenag Kabupaten Malang. Adapun perhitungan waktu shalatnya sebagai berikut :

Contoh perhitungan awal waktu Dzuhur untuk daerah Markaz Kab. Malang, Poncokusumo, dan Ngantang :

\section{Data :}

Lintang tempat $(\varphi)$

:759’ LS (markaz poncokusumo), $7^{\circ} 49^{\prime}$ LS (Ngantang)

Bujur tempat $(\lambda)$

$$
\begin{array}{ll}
: \text { Markaz } & : 112^{\circ} 36^{\prime} \mathrm{BT} \\
\text { Poncokusumo } & : 112^{\circ} 55^{\prime} \mathrm{BT} \\
\text { Ngantang } & : 112^{\circ} 18^{\prime} \mathrm{BT}
\end{array}
$$

Deklinasi matahari untuk waktu ashar adalah jam 09 GMT : 4 $22^{\prime} 21^{\prime \prime}$

Equation of time : Dzuhur jam 06 GMT $=-0^{\circ} 4^{\prime} 06^{\prime \prime}$

Koreksi Waktu Daerah (KWD) :

$$
\begin{array}{lllll}
\text { Markaz } & =\left(105-112^{\circ} 36^{\prime}\right): 15=-0^{\mathrm{j}} & 30^{\mathrm{m}} & 24^{\mathrm{d}} \\
\text { Poncokusumo } & =\left(105-112^{\circ} 55^{\prime}\right): 15=-0^{\mathrm{j}} & 31^{\mathrm{m}} & 40^{\mathrm{d}} \\
\text { Ngantang } & =\left(105-112^{\circ} 18^{\prime}\right): 15=-0^{\mathrm{j}} & 29^{\mathrm{m}} & 12^{\mathrm{d}}
\end{array}
$$

\section{Proses Perhitungan:}

Awal waktu Dzuhur untuk daerah Markaz Kab. Malang

Rumus awal waktu Dzuhur $=(12-\mathrm{e})+\mathrm{Kwd}+\mathrm{i}$
$M P=(12-e)=12-\left(-0^{\mathrm{j}} \quad 30^{\mathrm{m}} 24^{\mathrm{d}}\right)$
$=12^{\mathrm{j}} \quad 4^{\mathrm{m}} \quad 06^{\mathrm{d}}$
$\mathrm{t} / 15$
$=0^{\mathrm{j}} \quad 0^{\mathrm{m}} \quad 0^{\mathrm{d}}$
$\mathrm{KWD}=\left(105-112^{\circ} 36^{\prime}\right): 15$
$=-0^{\mathrm{j}} 30^{\mathrm{m}} 24^{\mathrm{d}}+$
Hasil perhitungan hakiki
$11^{\mathrm{j}} 33^{\mathrm{m}} 4^{\mathrm{d}}$
Hasil jika ditambah (i) $2^{\mathrm{m}}$
$11^{\mathrm{j}} 35^{\mathrm{m}} 42^{\mathrm{d}}$
Jadwal Kemenag Kab. Malang
$11^{\mathrm{j}} 36^{\mathrm{m}}$

Diperoleh kesimpulan bahwa selisih nilai antara perhitungan hakiki dengan jadwal kemenag kab. Malang adalah:

Jadwal Kemenag kab. Malang

Hasil perhitungan hakiki

Selisih

$$
\begin{aligned}
& =11^{\mathrm{j}} 36^{\mathrm{m}} \\
& =11^{\mathrm{j}} 33^{\mathrm{m}} 42^{\mathrm{d}}
\end{aligned}
$$

Awal waktu Dzuhur untuk daerah Poncokusumo kab. Malang

Rumus awal waktu Dzuhur $=(12-\mathrm{e})+\mathrm{Kwd}+\mathrm{i}$
MP $=(12-\mathrm{e})=12-\left(\begin{array}{lll}-0^{\mathrm{j}} & 30^{\mathrm{m}} & 24^{\mathrm{d}}\end{array}\right)$
$=12^{\mathrm{j}} 4^{\mathrm{m}} 06^{\mathrm{d}}$
$\mathrm{t} / 15$
$=0^{\mathrm{j}} 0^{\mathrm{m}} 0^{\mathrm{d}}$
$\mathrm{KWD}=\left(105-112^{\circ} 55^{\prime}\right): 15$
$=-0^{\mathrm{j}} 31^{\mathrm{m}} 40^{\mathrm{d}}+$
Hasil perhitungan hakiki
$11^{\mathrm{j}} 32^{\mathrm{m}} 26^{\mathrm{d}}$
Hasil jika ditambah (i) $2^{\mathrm{m}}$
$11^{\mathrm{j}} 34^{\mathrm{m}} 26^{\mathrm{d}}$
Jadwal Kemenag kab. Malang
$11^{\mathrm{j}} 36^{\mathrm{m}}$ 
Diperoleh kesimpulan bahwa selisih nilai antara perhitungan hakiki daerah Poncokusumo dengan jadwal kemenag Kab. Malang adalah:
Jadwal Kemenag Kab. Malang
$=\quad 11^{\mathrm{j}} 36^{\mathrm{m}}$
Hasil perhitungan hakiki
$=\quad 11^{\mathrm{j}} 32^{\mathrm{m}} 26^{\mathrm{d}}-$
Selisih
$=3^{\mathrm{m}} 34^{\mathrm{d}}$

Awal waktu Dzuhur untuk daerah Ngantang Kab. Malang

Rumus awal waktu Dzuhur $=(12-\mathrm{e})+\mathrm{Kwd}+\mathrm{i}$

$\mathrm{MP}=(12-\mathrm{e})=12-\left(-0^{\mathrm{j}} 30^{\mathrm{m}} 24^{\mathrm{d}}\right)$

$$
\begin{aligned}
& =12^{\mathrm{j}} \quad 4^{\mathrm{m}} 06^{\mathrm{d}} \\
& =0^{\mathrm{j}} \quad 0^{\mathrm{m}} \quad 0^{\mathrm{d}} \\
& =\underline{-0^{\mathrm{j}} 29^{\mathrm{m}} 12^{\mathrm{d}}}+
\end{aligned}
$$$$
\mathrm{KWD}=\left(105-112^{\circ} 18^{\prime}\right): 15
$$

Hasil perhitungan hakiki

Hasil jika ditambah (i) $2^{\mathrm{m}}$

Jadwal Kemenag kab. Malang

Diperoleh kesimpulan bahwa selisih nilai antara perhitungan hakiki daerah Ngantang dengan jadwal kemenag kab. Malang adalah:

Jadwal Kemenag kab. Malang

Hasil perhitungan hakiki

\section{Selisih}

$$
\begin{aligned}
& =11^{\mathrm{j}} 36^{\mathrm{m}} \\
& =11^{\mathrm{j}} 34^{\mathrm{m}} 54^{\mathrm{d}}- \\
& =\mathbf{1}^{\mathbf{m}} \mathbf{6}^{\mathbf{d}}
\end{aligned}
$$

Jika digambarkan dengan tabel, maka akan didapati selisih awal waktu dzuhur antara daerah Poncokusumo, Markaz, dan Ngantang adalah sebagai berikut:

\begin{tabular}{|l|c|c|c|}
\hline Daerah & Poncokusumo & Markaz & Ngantang \\
\hline Waktu hakiki & $11^{\mathrm{j} 32^{\mathrm{m}} 26^{\mathrm{d}}}$ & $11^{\mathrm{j}} 33^{\mathrm{m}} 42^{\mathrm{d}}$ & $11^{\mathrm{j}} 34^{\mathrm{m}} 54^{\mathrm{d}}$ \\
\hline $\begin{array}{l}\text { Jadwal kemenag kab. } \\
\text { Malang }\end{array}$ & \multicolumn{3}{|c|}{$\mathbf{1 1}^{\mathrm{j}} \mathbf{3 6}^{\mathrm{m}}$} \\
\hline SELISIH & $3^{\mathrm{m}} 34^{\mathrm{d}}$ & $2^{\mathrm{m}} 18^{\mathrm{d}}$ & $1^{\mathrm{m}} 6^{\mathrm{d}}$ \\
\hline
\end{tabular}

* hasil hakiki markaz \pm 2 menit

Contoh perhitungan awal waktu Ashar untuk daerah Markaz kab. Malang, Poncokusumo, dan Ngantang :

Data :

Deklinasi matahari untuk waktu ashar adalah jam 09 GMT

$$
\begin{aligned}
& =4^{\circ} 22^{\prime} 21^{\prime \prime} \\
& =-0^{\circ} 4^{\prime} 03^{\prime \prime}
\end{aligned}
$$

Equation of time Ashar jam 09 GMT

Koreksi Waktu Daerah (KWD) :

$$
\begin{aligned}
\text { Markaz } & =\left(105-112^{\circ} 36^{\prime}\right): 15=-0^{\mathrm{j}} \quad 30^{\mathrm{m}} 24^{\mathrm{d}} \\
\text { Poncokusumo } & =\left(105-112^{\circ} 55^{\prime}\right): 15=-0^{\mathrm{j}} \quad 31^{\mathrm{m}} 40^{\mathrm{d}} \\
\text { Ngantang } & =\left(105-112^{\circ} 18^{\prime}\right): 15=-0^{\mathrm{j}} \quad 29^{\mathrm{m}} 12^{\mathrm{d}} \\
\text { z Ashar } & =\tan [\mathrm{j}-\mathrm{d}]+1 \mathrm{à}(\text { Markaz dan Poncokusumo }) \\
& =\operatorname{shift} \tan \left(\tan \operatorname{abs}\left(-7^{\circ} 59^{\prime}-4^{\mathrm{o}} 22^{\prime} 21^{\prime \prime}\right)+1\right) \\
& =50,63774247 \\
& =50^{\circ} 38^{\prime} 15,87^{\prime \prime} \\
& =\tan [\mathrm{j}-\mathrm{d}]+1 \mathrm{à}(\text { Ngantang }) \\
& =\operatorname{shift} \tan \left(\tan \operatorname{abs}\left(-7^{\circ} 49^{\prime}-4^{\circ} 22^{\prime} 21^{\prime \prime}\right)+1\right) \\
& =50,63774247 \\
& =50^{\circ} 34^{\prime} 2,73^{\prime \prime} \\
& =\text { Cos t Ashar }=-\tan \mathrm{j} \times \tan \mathrm{d}+\sec \mathrm{j} \times \sec \mathrm{d} \times \cos \mathrm{z} \\
& =\operatorname{shift} \cos \left(-\tan -7^{\circ} 59^{\prime} \times \tan 4^{\circ} 22^{\prime} 21^{\prime \prime}+1 / \cos -7^{\circ} 59^{\prime} \times 1 / \cos 4^{\circ} 22^{\prime} 21^{\prime \prime} \times \cos 50^{\circ} 38^{\prime}\right. \\
& \left.15,87^{\prime \prime}\right)
\end{aligned}
$$


$=49^{\circ} 13^{\prime} 48,86^{\prime \prime}$ à (Markaz dan Poncokusumo)

$=$ Cos $\mathbf{t}$ Ashar $=-\tan \mathbf{j} \times \tan \mathbf{d}+\sec \mathbf{j} \times \sec d \times \cos z$

$=\operatorname{shift} \cos \left(-\tan -7^{\circ} 49^{\prime} \times \tan 4^{\circ} 22^{\prime} 21^{\prime \prime}+1 / \cos -7^{\circ} 49^{\prime} \times 1 / \cos 4^{\circ} 22^{\prime} 21^{\prime \prime} \times \cos 50^{\circ} 34^{\prime}\right.$ 2,73 ")

$=49^{\circ} 11^{\prime} 39,69^{\prime}$ 'à(Ngantang)

Proses Perhitungan:

Awal waktu Ashar untuk daerah Markaz Kab. Malang.

Rumus awal waktu Ashar $=(12-\mathrm{e})+(\mathrm{t} / 15)+\mathrm{Kwd}+\mathrm{i}$

$\mathrm{MP}=(12-\mathrm{e})=12-\left(-0^{\circ} 4^{\prime} 03^{\prime \prime}\right) \quad=12^{\mathrm{j}} 04^{\mathrm{m}} 03^{\mathrm{d}}$

$\mathrm{t} / 15=\left(\left(49^{\circ} 13^{\prime} 48,86^{\prime \prime}\right): 15\right) \quad=3^{\mathrm{j}} 16^{\mathrm{m}} 55,26^{\mathrm{d}}$

$\mathrm{KWD}=\left(105-112^{\circ} 36^{\prime}\right): 15$

$=-0^{\mathrm{j}} 30^{\mathrm{m}} 24^{\mathrm{d}} \quad+$

Hasil perhitungan hakiki

$14^{\mathrm{j}} 50^{\mathrm{m}} 34,26^{\mathrm{d}}$

Hasil jika ditambah (i) $2^{\mathrm{m}}$

$14^{\mathrm{j}} 50^{\mathrm{m}} 34,26^{\mathrm{d}}$

Jadwal Kemenag Kab. Malang

$14^{\mathrm{j}} 53^{\mathrm{m}}$

Diperoleh kesimpulan bahwa selisih nilai antara perhitungan hakiki dengan jadwal kemenag Kab.

Malang adalah:

Jadwal Kemenag kab. Malang $\quad=14^{\mathrm{i}} 53^{\mathrm{m}}$

Hasil perhitungan hakiki

Selisih

$=14^{\mathrm{j}} 50^{\mathrm{m}} 34,26^{\mathrm{d}}-$

Awal waktu Ashar untuk daerah Poncokusumo Kab. Malang

Rumus awal waktu Ashar $=(12-\mathrm{e})+(\mathrm{t} / 15)+\mathrm{Kwd}+\mathrm{i}$

$\mathrm{MP}=(12-\mathrm{e})=12-\left(-0^{\circ} 4^{\prime} 03^{\prime \prime}\right) \quad=12^{\mathrm{j}} 04^{\mathrm{m}} 03^{\mathrm{d}}$

$\mathrm{t} / 15=\left(\left(49^{\circ} 13^{\prime} 48,86^{\prime \prime}\right): 15\right) \quad=3^{\mathrm{j}} 16^{\mathrm{m}} 55,26^{\mathrm{d}}$

$\mathrm{KWD}=\left(105-112^{\circ} 55^{\prime}\right): 15$

Hasil perhitungan hakiki

$=-0^{\mathrm{j}} 31^{\mathrm{m}} 40^{\mathrm{d}}+$

Hasil jika ditambah (i) $2^{\mathrm{m}}$

$14^{\mathrm{j}} 49^{\mathrm{m}} 18,26^{\mathrm{d}}$

$14^{\mathrm{j}} 51^{\mathrm{m}} 18,26^{\mathrm{d}}$

Jadwal Kemenag kab. Malang

$14^{\mathrm{j}} 53^{\mathrm{m}}$

Diperoleh kesimpulan bahwa selisih nilai antara perhitungan hakiki dengan jadwal kemenag Kab. Malang adalah:

Jadwal Kemenag Kab. Malang $\quad=14^{\mathrm{i}} 53^{\mathrm{m}}$

Hasil perhitungan hakiki

Selisih

$=14^{\mathrm{i}} 49^{\mathrm{m}} 18,26^{\mathrm{d}}-$

Awal waktu Ashar untuk daerah Ngantang Kab. Malang

Rumus awal waktu Ashar $=(12-\mathrm{e})+(\mathrm{t} / 15)+\mathrm{Kwd}+\mathrm{i}$

$\mathrm{MP}=(12-\mathrm{e})=12-\left(-0^{\circ} 4^{\prime} 03^{\prime \prime}\right) \quad=12^{\mathrm{j}} 04^{\mathrm{m}} 03^{\mathrm{d}}$

$\mathrm{t} / 15=\left(\left(49^{\circ} 11,39,69^{\prime \prime}\right): 15\right) \quad=3^{\mathrm{j}} 16^{\mathrm{m}} 46,65^{\mathrm{d}}$

$\mathrm{KWD}=\left(105-112^{\mathrm{o}} 18^{\prime}\right): 15 \quad=\frac{-0^{\mathrm{j}} 29^{\mathrm{m}} 12^{\mathrm{d}}}{\mathbf{1 4}^{\mathrm{j}} \mathbf{5 1}^{\mathbf{m}} \mathbf{3 7 , 6 5}^{\mathrm{d}}}+$
Hasil perhitungan hakiki

Hasil jika ditambah (i) $2^{\mathrm{m}} \quad \mathbf{1 4}^{\mathrm{j}} \mathbf{5 3}^{\mathrm{m}} \mathbf{3 7 , 6 5 ^ { \mathrm { d } }}$

Jadwal Kemenag kab. Malang $\quad \mathbf{1 4}^{\mathrm{j}} \mathbf{5 3}^{\mathrm{m}}$

Diperoleh kesimpulan bahwa selisih nilai antara perhitungan hakiki dengan jadwal kemenag kab.

Malang adalah:

Jadwal Kemenag kab. Malang $\quad=14^{\mathrm{j}} 53^{\mathrm{m}}$

Hasil perhitungan hakiki $\quad=14^{\mathrm{i}} 51^{\mathrm{m}} 37,65^{\mathrm{d}}-$

Selisih

$=1^{\mathrm{m} 22,35^{\mathrm{d}}}$

Jika digambarkan dengan tabel, maka akan didapati selisih awal waktu Ashar antara daerah Poncokusumo, Markaz, dan Ngantang adalah sebagai berikut: 


\begin{tabular}{|l|l|c|c|}
\hline Daerah & \multicolumn{1}{|c|}{ Poncokusumo } & \multicolumn{1}{|c|}{ Markaz } & Ngantang \\
\hline Waktu hakiki & $14^{4} 49^{\mathrm{m}} 18,26^{\mathrm{d}}$ & $14^{\mathrm{j}} 50^{\mathrm{m}} 34,26^{\mathrm{d}}$ & $14^{\mathrm{i}} 51^{\mathrm{m}} 37,65^{\mathrm{d}}$ \\
\hline Jadwal kemenag kab. Malang* & \multicolumn{3}{|c|}{$\mathbf{1 4}^{\mathrm{j}} \mathbf{5 3}^{\mathrm{m}}$} \\
\hline SELISIH & $2^{\mathrm{m}} 25,7^{\mathrm{d}}$ & $1^{\mathrm{m}} 22,35^{\mathrm{d}}$ \\
\hline \\
$*$ hasil hakiki markaz \pm 2 menit. & $3^{\mathrm{m}} 41,7^{\mathrm{d}}$ & \\
\hline
\end{tabular}

\section{Hukum Seseorang yang Shalat dalam Masa Ihtiyath.}

Dalam contoh perhitungan awal waktu shalat di atas, untuk waktu ashar wilayah Poncokusumo kab. Malang pada tanggal 31 Maret 2012 secara hakiki dengan berpedoman pada data astronomi bujur $112^{\circ} 55^{\prime}$ BT dan lintang $7^{\circ} 59^{\prime}$ LS jatuh pada Pukul 14. 49. 18,26. Karena Poncokusumo merupakan wilayah kab.Malang, maka wilayah Poncokusumo menyesuaikan awal waktunya dengan markaz kab. Malang yang terletak pada bujur $112^{\circ} 36^{\prime}$ BT dan lintang $7^{\circ} 59^{\prime}$ LS. Secara hakiki, daerah markaz dinyatakan masuk waktu ashar pada pukul 14.50. 34,26, kemudian waktu hakiki pada markaz tersebut ditambah Ihtiyath \pm sebesar 2 menit, sehingga menjadi pukul 14.53 sesuai dengan jadwal yang dibuat kantor Kemenag Kab. Malang. Dari data di atas, peneliti mendapatkan selisih antara awal waktu hakiki daerah Poncokusumo dan awal waktu markaz yang telah mendapat tambahan Ihtiyath \pm 2 menit sebesar $3^{\mathrm{m}} 41,7^{\mathrm{d}}$. Dengan demikian, didapati simpulan bahwa karena mengikuti markaz yang ditambah Ihtiyath \pm 2 menit, daerah Poncokusumo mengalami perpanjangan waktu dzuhur selama 3 menit 41,7 detik. Menurut penulis, perpanjangan waktu shalat sebelumnya itulah yang menjadi problem terbesar pada masalah Ihtiyath.

Dewasa ini pemahaman dan semangat memahami masyarakat akan masalah-masalah keagamaan sangatlah minim. Masyarakat luas memahami bahwa berakhirnya waktu dzuhur ditandai dengan masuknya waktu ashar. Mereka tidak memahami bahwa jadwal shalat yang ada selama ini menggunakan Ihtiyath. Bukan menjadi rahasia lagi, banyak dari masyarakat kita yang suka untuk mengakhirkan waktu shalat. Jangankan mengakhirkan, secara kasat mata yang sudah tidak mengerjakan shalat jumlahnya lebih banyak. Meskipun demikian, bukan berarti keadaan yang seperti ini menyurutkan untuk menyuarakan perbaikan dalam hal pelaksanaan ibadah shalat.
Pertanyaan pertama yang muncul dalam benak peneliti setelah mengetahui selisih yang mencapai 3 menit 41,7 detik adalah bagaimana hukum shalat dzuhur pada masa tersebut. Pada bagian ini peneliti akan menggali hukum berdasarkan al Quran, hadits Nabi SAW, dan referensi-referensi fikih yang relevan dengan persoalan tersebut.

Berkaitan dengan status shalat yang dikerjakan di akhir waktu Rasulullah SAW bersabda:

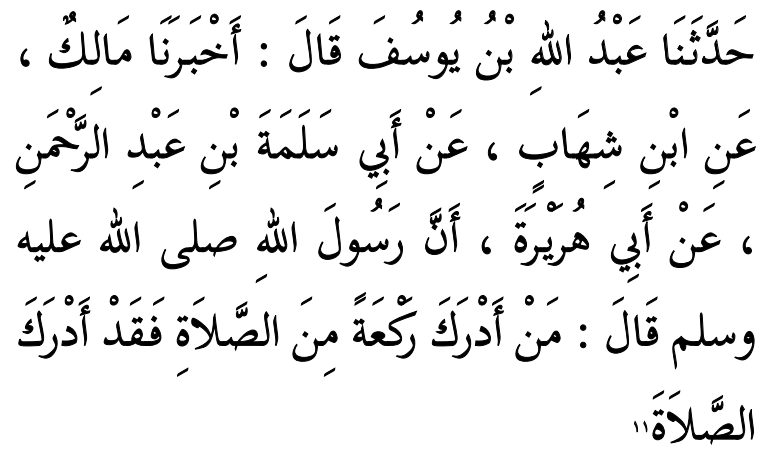

Dari Abu Hurairah, "sesungguhnya Rasulullah SAW bersabda: "barangsiapa yang mendapatkan satu rakaat dari shalat maka dia telah mendapatkan shalat".

Senada dengan kandungan hadits di atas, Rasulullah SAW bersabda:

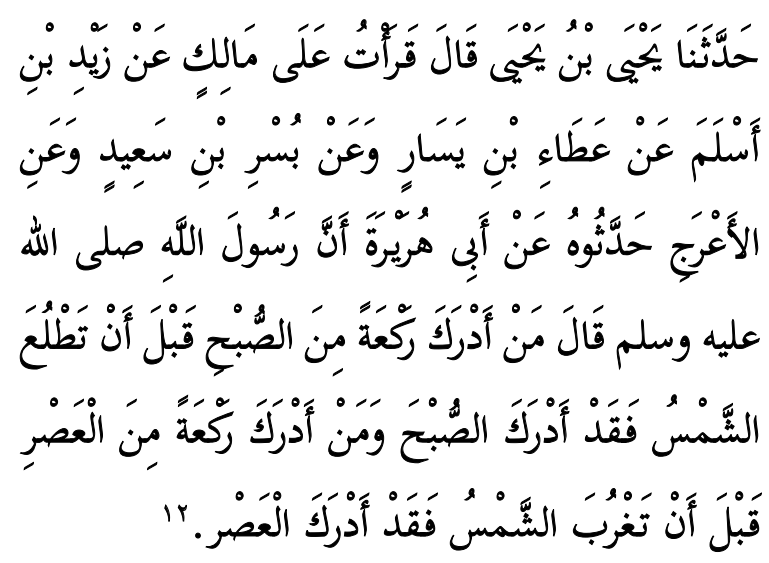

11 Al Bukhory, Jamii, h. 142

12 Muslim, Jamii, h. 102. 
Dari Abu Hurairah, "sesungguhnya Rasulullah SAW bersabda: "barangsiapayang mendapatkan satu rakaat shalat shubuh sebelum matahari terbit, maka dia telah mendapatkan shalat shubuh. barangsiapa yang mendapatkan satu rakaat shalat ashar sebelum matahari tenggelam, maka dia telah mendapatkan shalat ashar.

Dari dua hadits riwayat Abu Hurairah di atas peneliti berkesimpulan bahwa seseorang masih dianggap shalat adaa' jika telah mendapatkan satu rakaat pada waktu shalatnya,meskipun pada rakaat selanjutnya waktunya telah habis.

Dalam al Umm, Imam Syafii memberikan keterangan maksud dari matan hadits satu rakaat di atas adalah sebagai berikut:

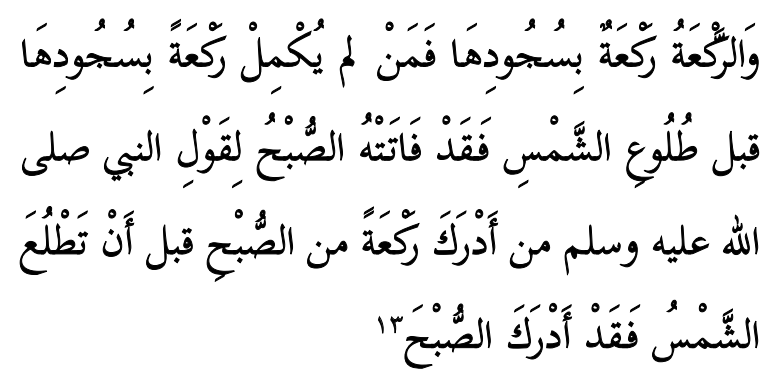

Satu rakaat adalah satu rakaat beserta sujudnya. Barangsiapa tidak menyempurnakan satu rakaat beserta sujudnya sebelum matahari terbit, maka dia telah tertinggal shubuh dengan berdasar hadits Nabi SAW "barangsiapa yang mendapatkan satu rakaat shalat shubuh sebelum matahari terbit, maka dia telah mendapatkan shalat shubuh."

Ibnu Hajar memberikan penguat dengan pernyataanya sebagai berikut:

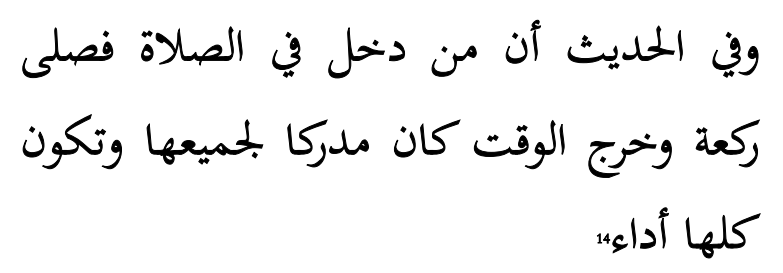

Disebutkan dalam hadits bahwa seseorang yang shalat masih satu rakaat kemudian habis waktu shalatnya, maka dia dianggap tetap shalat dalam keseluruhan dan masih dianggap adaan.

Dari dua hadits dan pendapat dua imam di atas peneliti berkesimpulan bahwa seseorang masih dianggap shalat $a d a a$ ' pada waktunyajika telah mendapatkan satu rakaat yang terhitung sampai melak-

13 Asy Syafi'i, al Umm, h. 75

14 Al Asqalaniy, Fathul baari, h. 56 sanakan sujud,meskipun pada rakaat selanjutnya waktunya telah habis.Menurut peneliti, hadits di atas berlaku pada konteks seseorang yang shalat sebelum masuk waktu hakiki waktu shalat setelahnya. Dengan penjelasan contoh sesuai dengan perhitungan yang telah dilakukan peneliti pada bagian terdahulu, secara hakiki daerah Poncokusumo pada tanggal 31 maret 2012 berakhir waktu dzuhurnya pada pukul 14. 49. 18,26 . Seseorang memulai shalat dzuhur pada pukul 14. 48. 00, kemudian saat berdiri rakaat kedua waktu menunjukkan pukul 14. 49. 18,26. Pada kasus seperti inilah hadits dan keterangan di atas berlaku.

Sedangkan dalam kitab Kifayatul Akhyar $f i$ Halli Gayatul Ikhtisarshalat dzuhur mempunyai enam waktu ${ }^{15}$, yaitu :pertama waktu fadhilah yaitu awalnya; kedua waktu jawaz yaitu hingga tinggal sekedar dapat menyelesaikan shalat;Ketiga waktu hurmah yaitu akhir waktu yang tidak sempat lagi menyelesaikan shalat seluruhnya dalam waktunya; dinamakan waktu itu waktu hurmah karena haram melambatkan mengakhirkan shalat sampai waktu tidak dapat menyelesaikan shalat dalam waktunya. Keempat waktu dharurah yaitu hilang mani' (penghalang) dari segala penghalang yang akan dalam waktu hanya tinggal lagi sekedar mengangkat takbiratul ihram. Kelima waktu $u d z u r$ yaitu waktu ashar yaitu waktu azar bagi orang musafir yang mengerjakan jamak ta'khir.Keenam waktu ikhtiar yaitu waktu jawaz. Inilah yang disebutkan dalam kitab "Tuhfah" seperti tercantum dalam kitab "Majmu" yang dinukil dari pendapat mayoritas ulama'. Dengan demikian, dalam pandangan imam Nawawi seseorang yang memulai shalat dzuhur pada pukul 14. 48. 00, kemudian saat berdiri rakaat kedua, waktu menunjukkan pukul 14 . 49. 18,26. Maka shalat yang seperti ini termasuk shalat yang dikerjakan pada waktu hurmah yaitu shalat yang dikerjakan di akhir waktu yang tidak sempat lagi menyelesaikan shalat seluruhnya dalam waktunya; dinamakan waktu itu waktu hurmah karena haram melambatkan mengakhirkan shalat sampai waktu tidak dapat menyelesaikan shalat dalam waktunya. ${ }^{16}$

Kemudian muncul pertanyaan "bagaimana dengan seseorang yang memulai shalat dzuhur di daerah Poncokusumo pada pukul 14.49. 18,26, bukankah saat itu belum masuk waktu ashar jika berpedoman pada jadwal Depag yang menetapkan awal waktu ashar masuk pada pukul 14. 53?" jika berpedoman pada pendapat waktu shalat dzuhur yang dikemukakan di dalam kitab Kifayatul Akhyar fi Halli

15 Al-Husaini,Kifayatul, h. 181-182

16 Al-Husaini,Kifayatul, h. 182 
Gayatul Ikhtisar, shalat dzuhur tersebut dikerjakan dalam waktu Keempat waktu dharurah yaitu hilang mani' (penghalang) dari segala penghalang yang akan dalam waktu hanya tinggal lagi sekedar mengangkat takbiratul ihram.

Allah SWT berfirman dalam surat Maryam ayat 59:

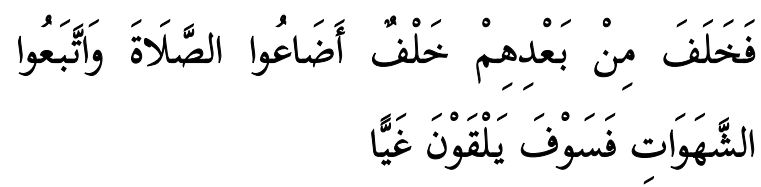

Maka datanglah sesudah mereka, pengganti (yang jelek) yang menyia-nyiakan shalat dan memperturutkan hawa nafsunya, Maka mereka kelak akan menemui kesesatan,

Ibnu Abbas menafsirkan ayat diatas bukanlah yang dimaksud menyianyiakan shalat itu hanya terbatas pada makna meninggalkan shalat secara mutlak, tetapi termasuk juga mengakhirkan shalat. Pendapat Saad bin musayyab dalam menyikapi ayat di atas adalah seharusnya seorang tidak shalat dhuhur sehingga datang waktu ashar, shalat ashar pada waktu maghrib, shalat maghrib pada waktu isya, shalat isya pada waktu shubuh, dan shalat subuh saat telah terbit matahari. Barangsiapa yang mati dalam keadaan shalat yang seperti ini, maka Allah menjanjikan baginya sebuah jurang di neraka jahannam yang dinamakan bagy. ${ }^{17}$

Rasulullah SAW bersabda:

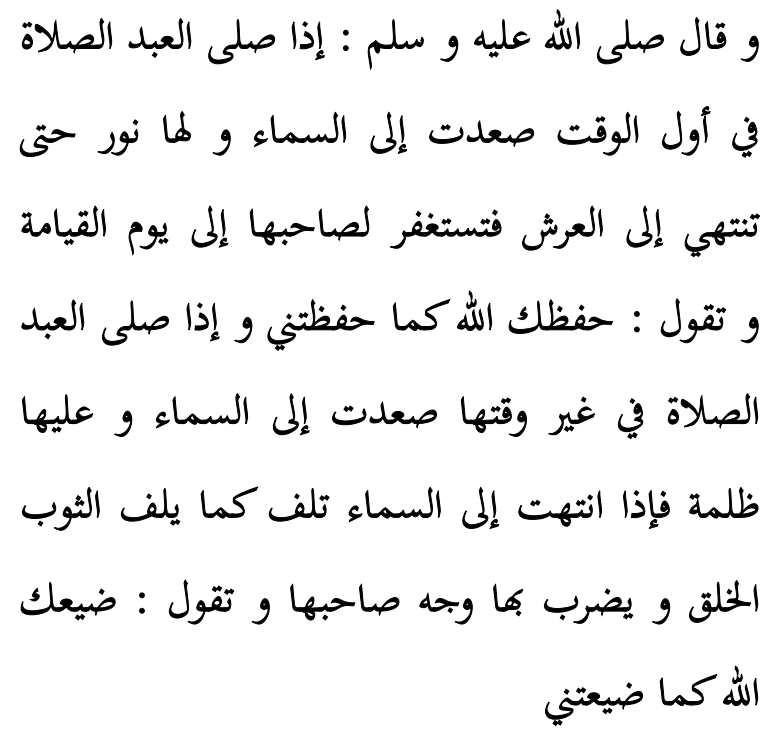

"Jika seorang hamba shalat pada awal waktunya, maka shalat itu akan naik ke langit dan

17 Adz Dzahabi,Kabaair, h. 14 bercahaya hingga berhenti di arsy, dan shalat tersebut senantiasa akan memohonkan istighfar bagi mushollinya hingga hari kiamat, seraya berkata: semoga Allah menjagamu sebagaimana engkau menjagaku. jika seorang hamba shalat selain pada waktunya, maka shalat itu akan naik ke langit dalam bentuk sebuah kegelapan. Sesampainya di langit, shalat itu dilipat-lipat sebagaimana baju yang kusut, kemudian shalat itu dihempaskan pada wajah mushollinya. Dan senantiasa shalat itu berkata: semoga Allah menyia-nyiakanmu sebagaimana engkau menyia-nyiakanmu." 18

Dalam hadits lain Rasulullah SAW bersabda:

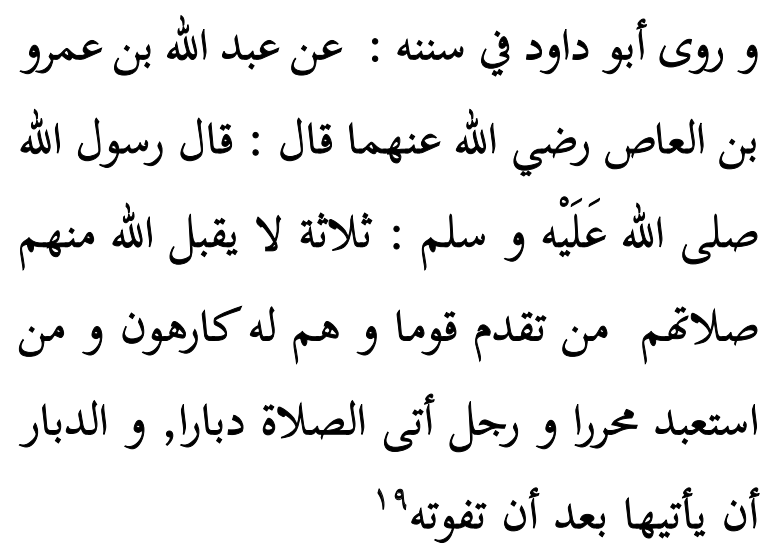

Dari Abu Dawud dalam sunannya dari sahabat Abdullah bin Amr bin Ash berkata, Rasulullah SAW bersabda: Allah tidak menerima shalat tiga golongan: seorang imam shalat yang tidak disukai makmumnya, seorang yang beribadah memakai sutra, dan seorang yang mengerjakan shalat di akhir waktunya. Akhir waktu dalam hadits ini bermakna setelah habis masanya.

Dari beberapa ayat al Quran, hadits, dan pen_ jelasan ulama, termasuk pendapat imam Syafii di atas peneliti berpendapat bahwa seseorang yang memulai shalat dzuhur di daerah Poncokusumo pada pukul 14. 49. 18,26 dikategorikan pada shalat yang tidak adaan, karena waktu yang tersedia tidak cukup untuk melaksanakan satu rakaat penuh beserta sujudnya.Sehingga shalat dzuhur pada waktu seperti ini, peneliti menyebutnya sebagai shalat yang dikerjakan di luar waktunya atau shalat dzuhur yang dikerjakan pada waktu ashar.Adapun hukum shalat dzuhurnya dihukumi shalat qadha.

Shalat yang di kerjakan di luar waktu seperti yang dilaksanakan di daerah Poncokusumo di atas

18 Adz Dzahabi, Kabaair, h. 17

19 Ibid., h. 17 
juga terjadi di daerah markaz kab.Malang, meskipun dalam waktu yang sangat sempit yakni \pm 2 menit. Seperti yang telah disebutkan pada bahasan sebelumnya dalam perhitungan jadwal waktu shalat untuk daerah markaz, pada tanggal 31 Maret 2012 untuk daerah markaz dengan titik koordinat wilayah $112^{\circ} 36^{\prime} \mathrm{BT}$ dan $7^{\circ} 59^{\prime}$ LS didapati hasil perhitungan hakiki awal waktu shalat ashar masuk pada pukul 14. 50. 34,26, jika berpedoman pada jadwal yang dibuat Kemenag Kabupaten Malang maka awal waktu ashar masuk pada pukul 14. 53. Dari hasil perhitungan hakiki dan hasil perhitungan Kemenag yang memasukkan unsur Ihtiyath \pm 2 menit, maka selisih waktu yang terjadi selama 2 menit 25,7 detik. Dan dalam kisaran dua mencapai tiga menit di atas, masyarakat sangat mungkin melaksanakan shalat dzuhur, tentunya mereka beranggapan bahwa selama adzan ashar belum berkumandang, shalat dzuhur masih dianggap adaan. Masyarakat tidak memahami bahwa adzan berkumandang pada umumnya berdasarkan jadwal waktu shalat yang dikeluarkan Kemenag atau lembaga-lembaga terkait, sedangkan jadwal tersebut telah mengalami penambahan Ihtiyath.

Sengaja peneliti hanya menampilkan hitungan hisab jadwal awal waktu shalat dan analisisnya hanya terbatas pada dzuhur dan ashar, hal ini peneliti lakukan karena peneliti memastikan akan mendapatkan hasil yang sama jika peneliti menghitung seluruh waktu shalat yang ada. Karena dalam aturan dan praktek perhitungannya semua menambahkan Ihtiyath.

Menurut peneliti dampak terberat adalah dalam penetapan awal waktu shubuh di bulan ramadhan. Memang dalam jadwal shalat Kemenag juga menampilkan waktu imsak. Tetapi peneliti temukan beberapa masyarakat masih ada yang berpedoman bahwa batas akhir sahur bukanlah imsak, tetapi terbitnya fajar yakni awal waktu shubuh, sedangkan mereka dalam menetapkan awal waktu shubuh berpedoman pada jadwal shalat yang telah ditambahkan Ihtiyath \pm 2 menit.Pertanyaan yang muncul adalah bagaimanakah status puasa mereka.

Disebutkan dalam kitab Bughyatul Mustarsyidin:

$$
\begin{aligned}
& \text { العبرة في دخول وقت الصلاة وخروجه بما وقته الشارع } \\
& \text { له لا بما ذكره المؤقتون ، وحينئذ لو غاب الشفق قبل } \\
& \text { مضي العشرين درجة التي هي قدر ساعة وثلث دخل } \\
& \text { وقت العشاء، وإن مضت ولم يغب لم يدخل كمافي }
\end{aligned}
$$

$$
\text { فتح الجواد }
$$

"Patokan Masuk dan habisnya waktu shalat berdasarkan ketentuan yang telah ditetapkan oleh syari', bukan berdasarkan apa yang telah disebutkan oleh ahli waktu (ahli hisab). Jika mega merah telah lenyap sebelum lewat 20 derajat atau sekitar satu jam lima belas menit maka saat itu dianggap sudah masuk waktu isya, atau jika telah lewat waktu sekitar satu jam lima belas menit tetapi mega merah masih ada, maka waktu isya belum masuk." 20

Keberadaan Ihtiyath jika ditinjau dari statemen yang ada dalam kitab Bughyah di atas, akan menghasilkan pernyataan bahwa waktu shalat yang hakiki didasarkan pada apa yang telah ditetapkan Allah, sehingga seseorang diharapkan tidak memandang bahwa jadwal yang dibuat oleh ahli falak adalah hasil final yang wajib dipatuhi. Jika ternyata di dalamnya terdapat masalah, selayaknya kita kembali pada apa yang telah ditetapkan Syari'.Keberadaan ilmu falak atau hisab adalah sebagai pembantu yang mempermudah kita memahami isi syara'.

\section{Kesimpulan}

Berdasarkan hasil penelitian tentang "Problematika Masa Ihtiyath Shalat Ditinjau Dari Ilmu Falak dan Fikih" maka dapat disimpulkan bahwasanya: Pertama, terdapat ketidaksearahaan antara definisi Ihtiyath yang dikemukakan oleh Depag RI dengan praktek perhitungannya. Menurut Depag RI, Ihtiyath merupakan langkah pengamanan dengan cara menambahkan atau mengurangkan waktu agar jadwal waktu shalat tidak mendahului awal waktu atau melampaui akhir waktu. Tetapi dari rumus yang ada dan hasil perhitungan jadwal shalat yang dibuat oleh Kemenag. Peneliti menemukan fakta bahwa Ihtiyath dalam proses perhitungan jadwal awal waktu shalat hanya ditambahkan tanpa ada proses pengurangan seperti definisi yang ditawarkan. Jika mengacu pada aplikasi perhitungan jadwal waktu shalat yang ternyata hanya menambahkan tanpa mengurangkan nilai Ihtiyath, konsekuensinya adalah mundurnya waktu shalat sebelumnya.Kedua, mengenai hukum seseorang yang shalat saat masa Ihtiyath terdapat dua kemungkinan. Kemungkinan pertama adalah jika seseorang shalat genap satu rakaat beserta sujudnya saat waktu hakiki, kemudian pada rakaat kedua masuk pada waktu Ihtiyath maka shalat seperti ini

\footnotetext{
20 Abdurrahman bin Muhammad Ba Alawi, Bughyatul mustarsyidin. (Semarang: Al haramain, $\mathrm{tt}$ ), h. 34
} 
masih dihukumi adaan. Kemungkinan kedua adalah jika seseorang shalat belum genap satu rakaat beserta sujudnya kemudian masuk waktu Ihtiyath maka shalat seperti ini masih dihukumi qadlaan, begitu juga jika seseorang yang shalat saat masa Ihtiyath.

\section{Saran}

Setelah mendalami dan menganalisis problem terkait Ihtiyath, peneliti dapat mengemukakan beberapa saran kepada pihak-pihak terkait, yaitu: (1) Untuk pemerintah dalam hal ini Kemenag RI: (a) Solusi terbaik adalah dengan peniadaan Ihtiyath dan markaz untuk satu wilayah kota atau kabupaten. Zaman telah maju, dengan kemajuan tersebut ditemukan beberapa alat canggih, seperti GPS yang dapat menentukan titik koordinat semua wilayah di permukaan bumi. Dengan berpedoman pada GPS ini, masing-masing masjid menghitung jadwal shalatnya dengan memasukkan dan lintang dan bujur masjid tersebut. Kemudian hasilnya diprogramkan dan dimasukkan pada jamjam digital canggih yang bisa diberi aplikasi-aplikasi tertentu seperti yang banyak kita lihat dewasa ini. (b) Solusi kedua adalah untuk daerah yang terlampau luas sebaiknya markaznya dibagi menjadi jadi dua

\section{DAFTAR PUSTAKA}

Abdul Karim bin Muhammad al Rafi' 'iy. Fath al 'Aziz bi Syarh al Wajiz, Beirut : dar el Kotob 2008.

Abdulloh bin Abdurrohman al Bassam, Taysirul Allam Syarh Umdatul Ahkam Maktabah Shahabat. Kairo 2006.

Adz Dzahabi, Syamsuddiin, Kitabul Kabaair, : al Haramain Tt.

Ahmad bin Hambal, Abu Abdillah, Musnad ahmad bin Hambal. Beirut: Dar el-Ma'rifah, 2004.

Al-'Asqalaniy,Ibnu Hajar, Bulughul al-Maram min Adillah al-Ahkam, Syirkah Al-Nur Asia, tt.

Al-'Asqalaniy,Ibnu Hajar, Fathul baari, Juz 8. Beirut: Dar el-Kotob, 2004.

Al-Banjari, Muhammad Arsyad, Sabilul Muhtadin, diterjemahkan Asywadie Syukur Lc, Sabilul Muhtadin, Surabaya: PT Bina Ilmu, 2005.

Al-Bukhari, Abu Abdillah Muhammad, Shahihul Bukhori Juz 1. Beirut: Dar el Kotob, 2010.

Al-Husaini, Abi Bakar Bin Muhammad. Kifayatul Akhyar fi Halli Gayatul Ikhtisar, diterjemahkan Syarifuddin Anwar dan Mishbah Musthafa, Kifayatul Akhyar (Kelengkapan Orang Saleh. atau lebih, tergantung luas daerahnya. Sehingga dengan pembagian ini diharapkan nilai Ihtiyath yang ditambahkan untuk mencakup daerah barat markaz semakin kecil. (c) Solusi terakhir adalah pemindahan markaz menuju arah timur semua, setelah itu diukur panjang kota atau kabupaten mulai dari timur sampai perbatasan di barat kota atau kabupaten. Setelah ditemukan maka panjang tersebut menjadi pertimbangan penentuan panjang Ihtiyathnya. (2) Untuk tokoh masyarakat dalam hal ini pemuka agama atau akademisi: (a) Melakukan penelitian-penelitian lanjutan yang berkaitan dengan masalah penentuan awal waktu shalat. (b) Memberikan dukungan atau masukan pada pemerintah agar mengkaji ulang kebijakan penambahan Ihtiyath. (c) Memberikan pengetahuan kepada masyarakat bahwa jadwal shalat yang ada saat ini telah ditambahkan Ihtiyath. (3) Untuk masyarakat: (a) Memperhatikan jadwal waktu shalat yang ada. Sehingga jangan sampai ada yang shalat di akhir waktu dan berdekatan dengan waktu setelahnya. (b) Memberikan dukungan kepada tokoh masyarakat dan pemerintah dalam upaya mewujudkan jadwal shalat yang lebih baik.

Surabaya : CV Bina Iman, 2007.

Al-Masyhur, Abdurrahman bin Muhammad Ba Alawi, Bughyatul mustarsyidin. Semarang: Al haramain, tt.

Al-Nawawi, Abu Zakariya bin Yahya,Raudhah al Thalibin, diterjemahkan H. Muhyiddin Mas Rida dkk, Raudhah al Thalibin, Jakarta : Pustaka Azzam, 2007.

Amiruddin dan Zainal Asikin, Pengantar Metode Penelitian Hukum, Jakarta: PT. Raja Grafindo Persada, 2004.

Asy-Syafi'i, Muhammad bin Idris,al Umm.Juz 1.Beirut: Dar el-Ma'rifah, 2004.

Azhari, Susiknan,Ilmu Falak Teori dan Praktek, Yogyakarta: Lazuardi, 2001.

Dadang, Ahmad Metode Penelitian Agama, Bandung: CV. Pustaka Setia, 2000.

Departemen Agama RI Pedoman Penentuan Jadwal Waktu Shalat Sepanjang Masa, 1994.

Encup Supriatna, Hisab Rukyat dan Aplikasinya, Bandung :Refika Aditama, 2007.

http: //jayusmanfalak.blogspot.com 
http://pcinu-mesir.tripod.com.

Lexy J. Maleong. Metodologi Penelitian Kualitatif, Bandung: PT.Rosda Karya, 2005.

Murtado, Mohammad Ilmu Falak Praktis, Malang: Uin press. 2008.

Muslim, Abul Husain. Sahih Muslim.Juz 2. Beirut: Dar el-Kotob, 2008.
Soerjono Soekanto, Pengantar Penelitian Hukum (Jakarta: UI Press, 1986)

Sutrisno Hadi, Metodologi Research Jilid I (Yogyakarta:Andi offset,1993)

Tim Dosen Fak. Syari'ah, Buku Pedoman Penulisan Karya Ilmiah. Malang: Fakultas Syari'ah UIN, 2011. 